Abilene Christian University

Digital Commons@ACU

$3-22-2018$

The Ethnographer's Circle: Institutionalizing Ethnography in the

Pacific Sociological Association

Daniel Morrison

Follow this and additional works at: https://digitalcommons.acu.edu/comm_socio

Part of the Sociology Commons 


\section{The Ethnographer's Circle: Institutionalizing Ethnography in the Pacific Sociological Association}

Sociological Perspectives 2018, Vol. 6I(2) 195-206

(C) The Author(s) 2018

Reprints and permissions:

sagepub.com/journalsPermissions.nav

DOI: $10.1177 / 073|12| 4 \mid 8756548$ journals.sagepub.com/home/spx

(SAGE

This volume of Sociological Perspectives is a long time coming. It is the capstone to six years of work by "The Ethnographer's Circle," a group of scholars dedicated to advancing the craft of ethnographic research and writing. The collected articles demonstrate the strength of ethnography on the West coast and beyond. The Ethnographer's Circle has hosted an array of scholars at the Pacific Sociological Association (PSA) Annual Meetings, from early-career graduate students to full professors. Our project centers on cultivating new ethnographic work that is at once richly empirical and deeply engaged theoretically. One measure of our success is that the Circle is now drawing scholars not just from the West coast but from across the country. What started as a small group of individuals has grown into something of national significance in a way that we never thought possible. Perhaps it is because PSA has provided the ideal venue to cultivate a creative space for ethnographers and our work. ${ }^{1}$ The articles that comprise this special issue were not just pieces solicited from the authors; they are the collaborative product of hard intellectual work and commitment. That labor warrants an explanation, and so we open the special issue of Sociological Perspectives on ethnography with that backstory, then discuss our vision for the special issue, and conclude with a brief overview of the articles that follow.

The origin of this special issue dates back to Thursday March 22, 2012, at 3:30 P.S.T. during the PSA Annual Meeting in San Diego. Black Hawk Hancock organized a panel titled "The Ethnographic Imagination and Shoe Leather," where a handful of junior ethnographers from around the country were invited to participate in an open discussion about the politics of ethnography and the challenges ethnographers face in publishing their work. Although the program listed paper titles, we planned a more free-form discussion of contemporary issues in the field.

To our surprise, the room was packed. All the seats were filled with several people taking space in the doorway. Black Hawk started by asking each panelist to describe their reaction to the American Journal of Sociology (AJS) debates and how the controversy that emerged affected their own work and perceptions of the field. As this was an unusual start, one senior faculty member in the audience raised his hand. When recognized, he asked about the papers listed in the program and expressed dissatisfaction with our approach to the panel, that is, that we were not discussing specific ethnographic works. The question brought panelist Dan Morrison into the conversation. He broke the "fourth wall," explaining that we were not reading papers, but rather holding an open and honest discussion of the politics and pitfalls of conducting ethnographic research. As the crowd murmured and glances were exchanged, Morrison offered the opportunity for those who wanted to hear other papers to leave the room. While that professor did leave, the rest remained seated, deeply engaged for 90 minutes. We held a lively discussion about the challenges of publishing ethnography both in article and book formats. In addition, several audience members raised their own stumbling blocks regarding publication, most importantly how to handle peer-reviews, especially those that appeared to be hostile critiques from other ethnographers.

These questions not only stimulated debate among the panelists but also stirred a rousing discussion in the audience. Thus, a panel became a group discussion. No one left in the middle of the session. After the session, several audience members pulled their chairs into a circle and 
continued to talk. It was not until the next session had to start, and we were literally pushed out of the room that the group broke up, but the conversation spilled out into the hallway and down into the lobby for another half hour. At least a dozen people remained to continue on with what we started.

The conversation did not end there. Black Hawk and David Yamane were out late that night, enjoying a slice of pizza on the sidewalk in the Gaslamp district, when three graduate students approached us and began asking more questions about the panel. At 2:30 a.m., we had clearly tapped into something that people were excited to discuss. Ending a night of reverie surrounded by a group of graduate students continuing to ask questions, as if this were an informal office hour, was the most unlikely end to an evening as we could imagine. What started almost 12 hours earlier just did not want to go quietly into the night.

The effervescence that this panel created was both surprising and energizing. This did not just move the audience and the presenters; it was also something that the PSA organizers noticed. With notoriety came resources, and in 2013, Dennis Downey and Chuck Holm (our funder) supported a wine and cheese reception to promote ethnography at PSA.

With the support and enthusiasm for ethnography at the PSA meetings mounting, we wanted to formalize our collaborations into something with official standing at the meetings. Our goal was to focus on ethnography as a substantive area, which connects the details of local meaning and cultures to larger social forces. We envisioned ethnography as a field of inquiry that uses interpretation, in the spirit of Clifford Geertz, to undertake social analysis as always embedded in a particular locale, yet always shaped by larger structural forces and mechanisms. The substantive area of concern is the explanatory aspect of ethnography, the relationship between theory and data, and one that moves from the micro to the macro in explaining the social world. As a substantive area, ethnography is distinct from ethnography as a technique in qualitative research. Our goals were to organize ethnographers and showcase ethnographic work, to provide a conduit for discussion, to ensure spaces for formal and informal exchange, and to cultivate ethnography at PSA. Accomplishing these goals, we reasoned, would enhance the professional interests of people in the area of ethnography, as well as promote ethnography to the members of PSA, and to the Pacific region in general.

In that spirit, we informally created a working group known as "The Ethnographer's Circle" to coordinate our multiple activities and advance our goals. Within the group, we sought to create exchanges across areas of specialization, presenting ethnographic work along its various stages, from formal presentations of finished works, to works in progress. We further envisioned workshops, author-meets-critics sessions, and teaching panels whereby formal and informal modes of mentoring and disciplinary discussion could unfold. ${ }^{2}$ All of these have come to fruition as the Ethnographer's Circle expanded its reach and influence.

Our next step was to organize a series of panels titled "The Ethnographer's Circle Workshop" created out of the desire to foster community among ethnographers. Here, we gathered together groups of two to four ethnographers who had works-in-process, asking them to exchange a working draft three weeks before the conference, along with a specific concern or two, from theory to analysis, with which they were wrestling. In this way, each scholar had to reflect on another's work, encouraging everyone to offer their most constructive feedback. The ultimate aim was to rely on each other to improve the work.

Our idea for The Ethnographer's Circle Workshop was not limited to exchange and dialogue between panelists. We created research in progress sessions, open to the public. To facilitate audience engagement and questions, each ethnographer briefly discussed his or her work, the issue he or she was having, and how he or she was trying to move forward. The other ethnographer who had read and commented on the work would then step in and engage the work, discuss what he saw as the problem, and offer possible solutions or suggestions for revision. The idea of starting in-media-res, rather than just discussing the merits of finished work, aimed to help the panelists 
advance and to engage audiences in ethnographic process. Each research-in-progress session engaged two questions: How can those different projects speak to each other despite their different topical issues? How can this exchange help other ethnographers in their thinking, writing, and problem solving in the generative spirit of a collaborative ethnographic community?

With the success of The Ethnographer's Circle workshops, ethnography became recognized and institutionalized as its own topical area on the PSA program. Once officially on the program, we sought to maximize the number of panels, creating thematically organized sessions, such as medical, gender, and symbolic interaction; theoretically oriented panels to think about the development of theoretical tools or the testing of theoretical frameworks in the case of ethnography; and shared concerns or problematics in writing ethnography. In addition to continuing The Ethnographer's Circle workshops, we created panels on the craft of ethnography (the practice of, politics within, poetics of writing, creative techniques of teaching ethnography, specific methodological issues within ethnography related to the larger discipline of sociology), author-meetscritics sessions, keynote speakers, and considering way to engage in forms of pubic ethnography.

\section{The Craft of Ethnography}

Here, we turn to highlight a few of the panels we have assembled over the years. The panels, as well as the slate of participants, have continued to evolve.

\section{Shop-talk: A Candid Discussion of the Politics and Pitfalls of Ethnography's (Not So) Open Secrets}

Building on the panel "The Ethnographic Imagination and Shoe Leather," we continued to hold panels that invited open-ended conversation about the not-so-hidden politics and problems confronting those who engage in the ethnographic enterprise. This panel addressed issues such as how does ethnography count toward tenure given its time investment versus production of articles/manuscripts, and how to strategize publications when ethnography tends to lend itself more to book format that to journal articles. Furthermore, we continued to discuss the issue of what the ethnographer does when confronted with the charge that he or she needs an American Journal of Sociology/American Sociological Review publication to go on the job market, or to improve one's job status.

\section{The Politics and Poetics of Ethnography: Ethnographers on the Craft of Fieldwork}

Expanding out from concerns of politics and professionalization, we addressed the internal architecture of ethnography in terms of research design, the construction of narrative, and how to write ethnography such that it captures the texture of everyday life while rendering the particular world under analysis within a wider context. Furthermore, the panel explored the types of data that ethnographers choose to focus on, recognizing that other foci are possible. This panel moved beyond the politics of the occupation, as both panelists and audience realized that we needed to address the aesthetic concerns and choices ethnographers must make in undertaking their work.

\section{Notes from the Field: Ethnographers on the Craft of Fieldwork}

Another iteration of our original panel focused on the multiple ways that we learn the craft of ethnography, a practice that does not easily lend itself to following the formulaic approaches in textbooks or "guides" to qualitative research. In addition, we discussed the daunting reality of how ethnography is less something that is directly taught, and instead is often something that we learn in the field alone or along the way in the experience of conducting fieldwork. Finally, we 
discussed the change in constraints from being a graduate student with rather unbounded time to pursue fieldwork, to the constraints that face the ethnographer once employed at an academic institution. The responsibilities of teaching, advising, service work, and the changing requirements for tenure and promotion most ethnographers face all necessarily undermine the kind of intensive immersion advocated by ethnographers of all orientations. As a result, we have seen recent changes in ethnography, specifically the much heavier reliance on interviews in later work as opposed to field observations among those who have produced a major ethnographic work while on the tenure-track.

\section{Validity and Generalizability in Ethnography}

This panel explored the elasticity and limitations of discussing ethnographic work in terms of "validity" and "generalizability." We debated the strengths and weaknesses of how ethnography can sustain validity in any sense, when field sites change, populations disperse, and places become obsolete, such that one "never steps into the same river twice." As a result, the panel dealt with thinking through the issue of "proving" that the case at hand faithfully represents the real world. Furthermore, the panelists debated issues of generalizability, in terms of what any specific ethnographic case can say about social life more generally. Does ethnography have validity? Does it have generalizability? On one hand, it was argued that ethnographers should adopt their own language and standards by which their work is assessed. This line of thinking is meant to reject the dominant quantitative logic of the discipline, which tries to compress qualitative analysis into quantitative concerns. On the other hand, it was argued that divorcing ethnographic work from "traditional" sociological concerns undermined its status as social science. In conclusion, the panel debated whether the rise of "mixed-methods" might offer an alternative to the all or nothing debate that seemed to be unfolding, as a way for both qualitative and quantitative work to be more reflexive and integrative with each other. While the panel ended contentiously, the placement of ethnography, either within the heart of the discipline or as an autonomous realm of inquiry, is a central issue that will continue to be explored. ${ }^{3}$

\section{Author-meets-critics Sessions}

The PSA Annual Meeting has become a preeminent space to showcase new work in ethnography, both published and in process. With only about a dozen authors a year selected for author-meetscritics panels at the American Sociological Association (ASA) Annual Meetings, there is a need for more such opportunities. A great many worthy books and authors do not get this opportunity, and the PSA has been a great egalitarian alternative to share outstanding ethnographic work with the public.

Our inaugural author-meets-critics session featured Hancock's American Allegory: Lindy Hop and the Racial Imagination (The University of Chicago Press 2013). ${ }^{4}$ Hancock's work examines the revival within white America of the Lindy Hop, the original Swing dance that emerged out of the ballrooms of Harlem in the late 1920s. It addresses the contradiction between the centrality of African American culture in American society and the simultaneous marginality of African American people. This essay reflects Hancock's own ethnographic experience to explicate the relationship between the racial imagination and an embodied approach to ethnography. He demonstrates how using the body as a phenomenological tool opens up new ways to think about both racial classification and cultural practices. He concludes with a discussion of what embodied ethnography offers us as a methodological approach to the study of social life. The focus of the session was to tease out the specifics and dynamics of "embodied sociology" such that it was both theoretically and methodologically something that could be applied to other areas of ethnographic inquiry. 
In Hancock's case, retooling of the body was a demanding process of inculcation and training whereby an awkward pre-dance body had to be re-formed and cultivated into an educated fluid dancing body. As with any practical activity one engages in, conceptual mastery of dance is of limited use; it is only after the dance has been assimilated into the body through endless drills and repetitions that it becomes fully understood. Only by embodying the dance could someone become a dancer, but also, and more importantly, could it allow the researcher to see and comprehend the details and subtleties that remain invisible to those who have not acquired that practical knowledge. Only through an embodied ethnographic approach could Hancock have come to understand the anxiety and tension that Lindy Hop dancers undertake consciously or unconsciously and the ways that race gets refracted through culture in learning how to dance. In concluding, the panelists focused in on how the embodiment of dance provided Hancock, as a sociologist, a tool for interpreting and understanding the world. ${ }^{5}$

In 2015, we hosted our second author-meets-critics session for Heather L. Talley's groundbreaking book Saving Face: Disfigurement and the Politics of Appearance. ${ }^{6}$ In this multi-sited ethnography, Talley tracks the social meaning of facial disfigurement and its travels across medicine, facial feminization, and popular culture. The result is a deeply moving account of the social meaning of the face, and the "face work" that goes into creating unremarkable faces. Talley suggests that our culture is simultaneously fascinated by beauty, but that the idea of beauty is premised on the "unremarkability" of so-called "normal" faces. Disfigurement, she argues, can be a kind of social death. People who carry the stigma of disfigurement often cannot accomplish normality, and may be thought unworthy of social protection and care. The stakes are high, as the very humanity of people with facial disfigurement is called into question. Specifically, by focusing on the "disfigurement imaginary," Talley's work takes us into the phenomenological/epistemological dimensions of what visual characteristics and facial features are needed to be "recognized" as a human being. Furthermore, her work engages the fundamental question of "what does it mean to be human?" She does so by examining the sociological processes that structure the social ontology of the human and how, through successful reconstructive surgery, recipients are brought into existence as fully recognizable, though "unremarkable" human beings. Talley's work powerfully addresses these concerns and was the winner of the Best Book award from the ASA Section on Body and Embodiment.

In 2017, PSA hosted Monica Casper from the University of Arizona. Monica discussed her book in progress, Babylost: An Infant Mortality Alphabet Book..$^{7}$ This work moves progressively through the alphabet from A to Z, offering readers at least one entry per letter. Selections from the opening include "Absence," "Angel Babies," and "Awareness." Her work crosses disciplinary boundaries, as she brings a critical, feminist science studies lens to the study of infant mortality. Not content with clinical definitions or sanitized numbers, this project tracks the ways that infant death is quantified and governed as "infant mortality." Casper's work focuses on the biopolitics of infant mortality, by framing risk assessment and other quantitative frameworks for the governance and clinical practice of infant life as a "portable abacus" for making sense of infant death. The book shows what is lost when focusing on quantification rather than the affective dimension of infant death: women's grief, family trauma, and various memorial practices. The project might be considered a departure from standard sociological accounts of infant death, yet it places central sociological concerns of the status of women, pregnancy, and reproductive capacities, especially those of marginalized women, at the heart of her work. In her trip through the alphabet, Casper shows us that to govern the fetus and to objectify infant death is to always govern women and women's bodies.

These are examples of author-meets-critics sessions past; we plan on making this a new cornerstone of the PSA meetings for ethnography moving forward. 


\section{Keynote Speakers}

Having established a place within the Annual Meetings, members of The Ethnographer's Circle were able to tap into our network of friends and colleagues, inviting well-known sociologists to keynote. When the PSA meetings were held in Oakland, Victor Rios' backyard, we had him deliver a keynote address on "The Politics of Ethnography: Race and Representation." Drawing on his own experiences, Rios took us into the heart of the inner-city lives of gang-affiliated Latino youth, documenting how these young men negotiate the institutions they encounter in everyday life by enacting multiple identities and drawing on a myriad of cultural frames. ${ }^{8}$ Rios discussed the tragic irony of how even well-intended educators and police officers "misfire" or miss their objectives and outcomes by failing to understand the cultural dynamics of the worlds of the young men they seek to reform. These failed outcomes lead youth into self-defeating identities and further increase their marginalization and stigmatization, resulting in school suspensions/expulsions, police harassment and humiliation, and disproportionate arrest and incarceration. Collectively, this social process leads to fewer economic opportunities and social resources, reinscribing inequality.

Without romanticizing or pathologizing, Rios argued that the ethnographer must pay exacting attention to the ways that the people under analysis are portrayed in all their capacities (emotional, psychological, intellectual, etc.). Failing to do so, he argued, risks using predefined categories and abstractions that dominate quantitative analyses. Alternatively, one risks falling into the "Jungle Book" trope whereby the ethnographic work turns into a self-indulgent narrative about one's experience of going native and living to speak about it, on returning to civilization. For Rios, ethnographers must defy stereotypes and mythologies of "gang-bangers" and "tales from the hood" that are so often pitfalls to scholarship, creating neither sanitized nor criminalized depictions, and instead ethnographers must view their work, their subjects, and their writing as all simultaneously constitutive of ethnography, which for him is both a scholarly and political project.

\section{Public Sociologies}

At the 2016 PSA meetings, Michael Burawoy gave the Presidential Plenary Lecture to a packed auditorium. Burawoy's talk "Sociology as a Vocation" offered his conceptualization of "public sociology" as walking two different paths. ${ }^{9}$ Public sociology in the "traditional" sense seeks to engage traditional publics through the dissemination of information through trade press books, newspapers, periodicals, social media, and so on. In contrast, public sociology in the "organic" sense focuses on face-to-face interaction with a multiplicity of publics, such as community organizations, hospitals, schools, trade unions, social movements, and so on. In either case, the public sociologist participates in civil society, which requires certain approaches and writing strategies to render his or her work accessible to public(s). This type of sociology must simultaneously maintain the integrity of the relationship to those publics and the scholarship about those publics, as well as ensure that the complexity of the research findings do not get distorted, simplified, or appropriated by those who may wish to use them for alternative purposes. ${ }^{10}$ Recognizing that scholars and scholarship are now in an age of commodification, marketization, and co-optation by private interests, Burawoy retains the link between public sociology, social problems and public policy, and the larger project of rescuing civil society itself. Irreducible to the economy or to the polity, civil society is the foundation for the diversity of opinions and values. For Burawoy, civil society is "the standpoint from which sociology evaluates the world, just as the market is the standpoint of economics and the state the standpoint of political science. Sociology arises with civil society and dissolves when civil society recedes" (Burawoy 2016:3).

Cecilia Ridgeway suggested that Black Hawk write up his response to Burawoy's address and send it to Contemporary Sociology, which accepted the work. Hancock's short response 
titled “Civil Society Must Be Defended: A Reply to Michael Burawoy's 'Sociology as a Vocation' from the Standpoint of Ethnography" took the opportunity to interrogate the work of ethnographers and ethnography itself. ${ }^{11}$ If sociology, and more specifically, "public sociology" as defined by Burawoy, is to be the defender of civil society, then what are the weapons and what are the costs of the fight? What happens if we fail? In attempting to answer this question on Burawoy's terms, Hancock explored "Sociology as a Vocation" from the standpoint of ethnography as a weapon for civil society's defense. Ethnography, as public sociology, comes with a number of caveats. First, ethnography must be written in a way that eschews jargon, while simultaneously not compromising its status as social science. Second, ethnography as public sociology must be accessible to the multiple competing and conflicting publics that comprise civil society. Third, our work must operate in response to the forces of marketization, the commodification of knowledge, and the disappearance of state funding that define the contours of universities and colleges where most ethnographers practice. Finally, changing requirements for tenure and promotion, such as journal articles and other professional writings strictly targeted to academics are valued more highly than work that engages the public. Collectively, social forces have changed the ways that ethnographers work, as well as how they must now think about the role and relevance of ethnography, as public sociology, for the defense of civil society. A fourth and final factor to consider is the mass media. We must confront how ethnography is often distorted by replacing the original work with someone else's summary, taken out of context, or conveyed through a partial or piecemeal perspective, and is, therefore, always subject to co-optation by powerful corporate and media interests. This confluence of factors makes ethnography a dangerous venture, because in making sociology accessible, one can easily fall into the traps of either sanitizing and romanticizing people or conversely pandering to public stereotypes and portraying the dominated as pathological. As a result, whether intentionally or unintentionally, ethnography can be put into the service of perpetuating the very inequality and domination social science seeks to unmask. Therefore, it is not just the production of ethnography that is of concern, but it is also the circulation and consumption of the work, which are often beyond the ethnographer's control.

By taking up "Sociology as a Vocation," ethnography can become a weapon for public sociology. With an organic approach to ethnography, we must seek to create a dialogue between the people we study and ourselves. Here, we work collectively trying to understand social life, often (but not always) across social and cultural difference. By working organically, we seek to write ethnography in ways that will be recognizable and resonate with the very people about whom the ethnography was written. In doing so, we must work together, so the people studied become invested in the ways their worlds are represented and, therefore, will defend themselves when called into question or distorted by others. We must work together and remain vigilant when monitoring the ways that mass media circulate and represent ethnographic work. In addition, ethnographers must tend to our own practices of defining our point of view within the field, creating a narrative style, relating to our subjects, and grappling with the politics of representation, all while undertaking our ethnographic work.

"Sociology as a Vocation" is not simply an appeal for public sociology, but it is the driving disposition required to defend civil society, and ethnography is one weapon to wield in its defense. "Sociology as a Vocation" reminds us that in the production of knowledge, the ethnographer must remember that he or she is just as much a part of the world as the people the ethnographer studies, and that the people the ethnographer studies are as much a part of civil society as the ethnographer. Following Burawoy, we must make a commitment to public sociology, to defend civil society, but there is no guarantee to securing that defense. We must also remember that without that commitment to defend civil society for us all, the people the ethnographer studies, and the ethnographer, may end up cultivating their own social obsolescence. 


\section{The Making of the Special Issue on Ethnography}

After organizing author-meets-critics and multiple panels at the Annual Meetings, we decided to take the work to a broader audience by proposing a special issue of Sociological Perspectives dedicated to ethnography in and beyond the PSA. This next step fully institutionalizes The Ethnographer's Circle and ethnography more generally at PSA. We think Sociological Perspectives should be a prominent venue for new ethnographic work that pushes the boundaries of the discipline. The papers that follow center around the three of the themes that have animated the work of The Ethnographer's Circle: (1) theoretical innovations by engaging a well-known body of existing theory, offering novel ethnographic approaches, uncovering new insights, and breaking theoretical ground; (2) thick descriptions and phenomenology, which cultivate descriptive clarity, to advance our understanding of a form of interaction, basic social process, or other social phenomena of interest; (3) methodological advances, which push the boundaries of existing ethnographic practice, either by advocating, or demonstrating, the utility of new approaches to ethnographic work.

\section{Contributions to the Special Issue}

Rejecting damage-centered accounts that pathologize black life, Marcus Hunter's "Black Logics, Black Methods: Indigenous Timelines, Race and Ethnography" features two emergent pathways for assets-based research: racial recalibration and black time. Drawing on his work Black Citymakers (2013), Hunter argues that ethnography is key to this effort. Hunter writes that our conventional timelines for black histories and contemporary realities are calibrated against white notions of time and history. His work, thus, reveals a persistent and specious practice that frames most well-known studies of black lifeworlds. In this, he extends Stuart Hall's discussion of the theoretical and analytic power of everyday black wisdom, storytelling, and popular culture. We think this article demonstrates how black perspectives, when measured and apprehended using race-conscious and assets-based frames provide generative, innovative questions and new ways to revisit long debated issues in the field. The paper clearly illustrates the strength of ethnography for generating theoretically rich analytic frameworks and capturing the subordinated knowledges and histories written within and against hegemonic accounts.

Jennifer Reich's contribution "II Have to Write a Statement of Moral Conviction. Can Anyone Help?' Parents' Strategies for Managing Compulsory Vaccination Laws" takes us into the tensions of liberty and community in contemporary U.S. context. Reich mines a paradox of public health: Requirements to vaccinate children have virtually eliminated some communicable diseases while the fact that so many have been vaccinated provides space for "free riders" who reject some or all of these vaccines. Reich shows how parents express frustration and resentment over lack of information regarding exemptions from vaccine requirements, and how they manage information about their children's vaccination status, often selecting some vaccines while rejecting others. Furthermore, the paper illustrates that many parents believe resisting vaccinations is part of their efforts to challenge state power, which they understand to be restricting their individual liberty. The paper concludes with a discussion of what this means for communities and the social contract more generally. We think this paper shows how ethnographers can both deeply engage with a mix of empirical materials while pursuing themes of interest to multiple audiences, such as democratic theory and questions of social obligation.

Sharon Oselin's paper offers a grounded theory approach to a classic issue in the sociology of deviance: stigma. Her work, "Challenging Stigma: Identity Work among Male Sex Workers in a Recovery Program" adds rich detail to our understanding of responses to stigmatized work within the context of a religiously affiliated recovery center. Oselin examines an old question in a new way, uncovering three stigma-management strategies that male sex workers employ. Men who 
engage in street-based sex work are especially susceptible to stigma due to their working conditions and the legal status of the trade. Oselin provides a new perspective on "identity talk" through ways that men craft personal identities that reclaim a sense, however minimal, of self-worth and dignity. Identity talk unfolds within a service-provision organization, A Lift Up, and men's relationship to this program and their views on prostitution influence their narratives. The findings highlight how identity talk influences and is influenced by behavior. Like Reich, Oselin leveraged multiple methods, including in-depth interviews and intensive participant observation at A Lift Up. Oselin's work illustrates how ethnographers in the Pacific region are simultaneously following major research traditions in the field, and offering new innovations on classic concepts.

Melanie Gast's “'They Give Teachers a Hard Time': Symbolic Violence and Intersections of Race and Class in Interpretations of Teacher-Student Relations" takes up Bourdieu's concept of symbolic violence along with an intersectional approach to understand how race and class influence student discourse about merit and inequality. Few scholars examine how the intersection of race and class influence interpretations of teacher-student relationships. Gast's deep engagement in life at Hillside High, a diverse school with both racial and social class stratification, allowed fresh insights into the racial and class-based sources of misrecognition that characterize teacherstudent relationships - for those at the bottom of the hierarchy. Gast documents how middleclass and some working class black Honors students shared their teachers' discourse about urban poor disengagement and "black" behavioral problems with teachers. At the same time, workingclass black (primarily non-Honors) students called out racism and mistreatment in light of experiencing punitive relations and problems with teachers; however, some of their teachers and peers interpreted calls of racism as "making excuses" for disengagement and misbehavior. Gast's powerful work demonstrates how language about black student-teacher relations allows school actors to misrecognize, and simultaneously legitimate, race-class classifications in a diverse school.

Susan Mannon's contribution "Misery Loves Company: Poverty, Mobility and Higher Education in the Post-welfare State" brings a fresh perspective on the relationship between poverty, mobility, and higher education in the contemporary United States. Like Gast, Mannon examines the question of social inequality and mobility. While Gast draws primarily on extended interviews and analysis of the discourses surrounding inequality, Mannon's autoethnographic approach provides another form of insight into these processes. In contrast to quantitative analyses, which have found robust and positive outcomes associated with college attainment, Mannon brings herself into the scene, offering an ethnographic perspective to tell a more complicated story about what college offers the poor. This story centers on a low-income woman of color named Angelica. Angelica's story of drug-addict-turned-college graduate suggests that college might be just as much a regulatory institution as a poverty solution. Mannon critically and reflexively assesses her own role as Angelica's former professor, professional mentor, and life narrator. Angelica is placed fully in context, which includes twentieth-century efforts to reform the welfare system and reduce the use of state-sponsored social safety nets. The article concludes by suggesting that college is no lifeline, but a mechanism by which Angelica and others are brought into the fold of a "respectable" but often miserable middle-class life, ironically exemplified by Mannon's own life as a scholar, teacher, spouse, and parent.

The next two articles take a step back and consider ethnographic methods, their relation to theory, and the recent move to multi-methods research. Both pieces forcefully argue that sociologists should pay much closer attention to the all-too-often unrecognized disjunction between their methods and theoretical frameworks. Researchers may uncritically adopt theoretical frames that shape case selection and fieldwork practice. Andrew Deener argues that building ethnographic knowledge is an incremental, iterative process. The process includes two steps: (1) narrowing down an interpretive framework through which ethnographers develop empirical observations as sociological data and (2) connecting the established understanding of the 
sociological units of observation with interpretations of formal and informal elements of time and space. These processes help the ethnographer contextualize the data to develop deeper layers of analysis. Deener's "The Architecture of Ethnographic Knowledge: Narrowing Down Data and Contexts in Search of Sociological Cases," thus, explicates the workings of, and relationships between, these hermeneutic and phenomenological processes as the underlying architecture of ethnographic knowledge. How ethnographers configure this scaffolding instructs the search for potential matches between theories and data.

Black Hawk Hancock, Bryan Sykes, and Anjuli Verma's article "The Problem of 'Cameo Appearances' in Mixed-methods Research: Implications for 21st-century Ethnography” closes the issue with a provocation to both ethnographers and quantitative scholars. Amid ongoing controversies in ethnography concerning representation, reproducibility, and generalizability, social scientific scholarship has increasingly taken a mixed-methods turn. While studies that blend qualitative and quantitative data promise to enhance the validity of representations of social worlds under analysis, they cannot escape contending with foundational dilemmas of scientific translation, integration, and commensurability across methodological paradigms. Recent debates have ignited a new line of inquiry about the integration of multiple methods in ethnography. The authors argue that "cameo appearances"- the summoning of either qualitative or quantitative analyses in separate, purely mono-method studies - amounts to a form of methodological tokenism under the guise of methodological pluralism. They recommend articulate sampling design, enhanced training, and curriculum development as crucial for arbitrating these debates as mixedmethods research emerges as a distinct innovation in twenty-first-century ethnography.

\author{
Black Hawk Hancock \\ DePaul University, Chicago, IL, USA \\ Daniel R. Morrison \\ Vanderbilt University, Nashville, TN, USA \\ ethnographerscircle.org
}

\title{
Acknowledgments
}

The authors would like to thank the following who have all contributed to The Ethnographer's Circle, ethnographic panels, workshops, and presentations, and others who helped us pull this special issue on ethnography together in one way or another: Jacob Avery, Lora Bristow, Michael Burawoy, Chas Camic, Matthew J. Carlson, Monica Casper, Mark Cohan, Dana Collins, Dean Dorn, Dennis Downey, Jennifer Eichstedt, Edward Flores, Alexander Frenette, Patricia Gwartney, Chuck Holm, Simone Ispa-Landa, Calvin Morrill, Alexandra Murphy, Wendy Ng, Amy Orr, Sarah M. Ovink, Robert Nash Parker, C. J. Pascoe, Cecilia Ridgeway, Victor Rios, Corey Shdaimah, Lindsey Wilkinson, Daniel Winchester, Elizabeth Withers, and Hyeyoung Woo.

\section{Special Acknowledgment}

A special acknowledgment needs to be given to Dennis Downey for his sage guidance, mentoring, and continued friendship. The Ethnographer's Circle and this special issue would not have been possible without his support.

\section{Declaration of Conflicting Interests}

The author(s) declared no potential conflicts of interest with respect to the research, authorship, and/or publication of this article.

\section{Funding}

The author(s) received no financial support for the research, authorship, and/or publication of this article. 


\section{Notes}

1. For important historical analysis of the Pacific Sociological Association, see Dean Dorn $(2005,2014)$ and Dennis J. Downey and Charles Hohm (2014).

2. Matthew Carlson and Tina Burdsall (2014), Dennis J. Downey and Amy Orr (2014), Patricia Gwartney (2014), Valerie Jenness and Dennis Downey (2012), Amy Wharton (2014).

3. Much of this discussion revolves around Bryan Sykes, Anjuli Verma, and Black Hawk Hancock (2017).

4. Black Hawk Hancock (2013).

5. These comments were used as a springboard to explore how embodiment can assist the ethnographic enterprise more generally, in Black Hawk Hancock (2017).

6. Heather Talley (2014).

7. Monica Casper (forthcoming).

8. For the source material for this talk, see Victor Rios $(2011,2017)$.

9. Michael Burawoy (2016).

10. Gary Alan Fine and Black Hawk Hancock (2016:15-16).

11. This is a slightly revised version of Black Hawk Hancock (2016).

\section{References}

Burawoy, Michael. 2016. "Sociology as a Vocation.” Contemporary Sociology 45(4):379-93.

Carlson, Matthew and Tina Burdsall. 2014 "Research-in-progress Sessions Create a More Inclusive and Engaging Regional Conference." American Sociologist 45:177-79.

Casper, Monica. 2017. "Babylost: An Infant Mortality Alphabet Book" Paper presented at the Annual Meeting of the Pacific Sociological Association, April 7, Portland, OR.

Dorn, Dean. 2005. Seventy-five Years of the Pacific Sociological Association, 1929-2004. Sacramento, CA: Pacific Sociological Association.

Dorn, Dean. 2014. "A Brief History of the Pacific Sociological Association." American Sociologist 45:121-33.

Downey, Dennis J. and Charles Hohm. 2014. "Guest Editors' Introduction: Considering Regional Sociological Associations." American Sociologist 45:115-20.

Downey, Dennis J. and Amy Orr. 2014. "Between Scylla and Charybdis: Designing, Implementing, and Assessing Innovations in the Annual PSA Meetings." American Sociologist 45:159-76.

Fine, Gary Alan and Black Hawk Hancock. 2016. "The New Ethnographer at Work." Qualitative Research 17(2):260-68.

Gwartney, Patricia. 2014. "Elite Dilution or Saved by the Belles? The Changing Social Demography of the Pacific Sociological Association." American Sociologist 45:226-48.

Hancock, Black Hawk. 2013. American Allegory: Lindy Hop and the Racial Imagination. Chicago, IL: The University of Chicago Press.

Hancock, Black Hawk. 2016. "Civil Society Must Be Defended: A Reply to Michael Burawoy's 'Sociology as a Vocation' from the Standpoint of Ethnography." Contemporary Sociology 45(5):675-76.

Hancock, Black Hawk. 2017. "Embodiment: A Dispositional Approach to Racial and Cultural Analysis." Pp. 155-183 in Approaches to Ethnography: Analysis and Representation in Participant Observation, edited by Colin Jerolmack and Shamus Kahn. Oxford, England: Oxford University Press.

Hunter, Marcus. 2013. Black Citymakers: How the Philadelphia Negro Changed Urban America. New York: Oxford University Press.

Jenness, Valerie and Dennis Downey. 2012. "Changes Coming to PSA Program Development Process for 2013 Meetings in Response to Member Concerns and Council Recommendations." The Pacific Sociologist 20(2):2-3.

Rios, Victor. 2011. Punished: Policing the Lives of Black and Latino Boys. New York: New York University Press.

Rios, Victor. 2017. Human Targets: Schools, Police, and the Criminalization of Latino Youth. Chicago, IL: The University of Chicago Press. 
Sykes, Bryan, Anjuli Verma, and Black Hawk Hancock. 2017. "Aligning Sampling and Case Selection in Quantitative-qualitative Research Designs: Establishing Generalizability Limits in Mixed-method Studies.” Ethnography. Published electronically August 21. Doi:10.1177/1466138117725341.

Talley, Heather. 2014. Saving Face: Disfigurement and the Politics of Appearance. New York: New York University Press.

Wharton, Amy. 2014. "The Past, Present, and Future of a Regional Sociological Association." American Sociologist 45:327-33.

\section{Author Biographies}

Black Hawk Hancock is an associate professor of sociology at DePaul University. He is the author of American Allegory: Lindy Hop and the Racial Imagination (The University of Chicago Press). His work has appeared, among other places, in Ethnography, Journal of Contemporary Ethnography, Qualitative Research, and Qualitative Sociology. His new book manuscript In-Between Worlds: Mexican Kitchen Workers in Chicago's Restaurant Industry is currently under contract with The University of Chicago Press.

Daniel R. Morrison is a senior lecturer in sociology and special assistant to the senior associate dean for undergraduate education in the College of Arts and Science at Vanderbilt University. His research has appeared in The Journal of Health and Social Behavior, Disability Studies Quarterly, American Journal of Bioethics, and the Journal of Medicine and Philosophy, among other venues. He is at work on two book projects: the first, on care and democratic theory, and the second, on pragmatic interactionism. 